\title{
Aseptic Viral Meningitis Secondary to Herpes Simplex Virus 2 Genital Infection
}

\author{
Camille Marshall $^{1}$, Zachary T. Clark ${ }^{2}$, Michael R. Minckler ${ }^{3}$ \\ 1. Biology, Whitman College, Walla Walla, USA 2. Molecular Biology, Whitman College, Walla Walla, USA 3. Emergency \\ Medicine, Providence St. Mary Medical Center, Walla Walla, USA
}

Corresponding author: Zachary T. Clark, zachtwin1@gmail.com

\begin{abstract}
Aseptic viral meningitis is the most common cause of meningitis in the United States. Most cases of herpes simplex virus meningitis are caused by herpes simplex virus type 2 (HSV-2), with HSV-1 primarily causing viral encephalitis. In this report, we present a case of aseptic meningitis generated by the HSV-2 in an immunosuppressed 35-year-old female with a recent diagnosis of genital herpes that was left untreated due to reported side effects of medication.
\end{abstract}

Categories: Emergency Medicine, Allergy/Immunology, Infectious Disease

Keywords: viral meningitis, aseptic meningitis, herpes simplex virus, immunocompromised

\section{Introduction}

As the prevalence of compromising immunological conditions increases, the incidence of viral meningitis (VM) including herpes simplex virus type 2 (HSV-2) will also likely increase. These compromising conditions may include an aging population and diabetes. In 2003, the Centers for Disease Control and Prevention estimated that VM results in between 26,000 and 42,000 hospitalizations each year [1]. The incidence of VM in the United States has been estimated to be $0.26-17$ cases per 100,000 people [2]. A prospective cohort study published in 2018 by Fiona McGill et al. showed that in United Kingdom adults, 55\% of VM cases were caused by enteroviruses, followed by HSV as the second most common cause at 44\% [3]. Such cases must be recognized and treated promptly in order to avoid increased complications and possible neurologic sequelae [4-6]. Neurologic sequelae of VM, such as chronic headaches, short-term memory loss, paresthesia or sensory deficits, and discoordination, can be severe in the short and long term $[3,4,7]$. While antivirals are currently recommended for treatment of viral encephalitis, VM treatment with acyclovir and antivirals remains controversial and inconsistent. Supportive care remains the most common provision of treatment, as many patients may recover on their own [4]. However, Noska et al. suggest that neurologic sequelae could be decreased in immunocompromised patients with meningitis, from either HSV serotype, if they were treated with antivirals $[3,4,8]$.

Review began 11/19/2020 Review ended 04/14/2021 Published 04/17/2021

\section{○ Copyright 2021}

Marshall et al. This is an open access article distributed under the terms of the Creative Commons Attribution License CC-BY 4.0., which permits unrestricted use, distribution, and reproduction in any medium, provided the original author and source are credited.

\section{Case Presentation}

A 35-year-old female presented to the emergency department (ED) complaining of neck stiffness for one week, which had worsened over the previous 24 hours, and a gradual-onset headache. The pain was nonradiating, worse with both active and passive flexion, and rated at 10 out of 10 . The patient had tried taking ibuprofen, which provided no relief. The patient also reported body aches, chills, photophobia, and had a fever of $100.8 \mathrm{~F}$.

The patient has an underlying history of HSV-2. Two weeks ago, she was newly diagnosed with a genital herpes infection, which was likely contracted from her new sexual partner three months ago. She was prescribed oral acyclovir; however, she declined treatment due to reported facial swelling as a side effect due to acyclovir while taking it for shingles. Other medical history included acute myelogenous leukemia in remission since 1998, shingles, poorly controlled type 1 diabetes mellitus, and protein S deficiency. Her current medication included insulin aspart, alprazolam, ondansetron, and topical lidocaine. Social history was significant for a new sexual partner within the previous three months. She denied any tobacco, alcohol, or drug use.

Initial vital signs were a temperature of $100.8 \mathrm{~F}$, heart rate of 115 , respiratory rate of 18 , blood pressure of $152 / 96 \mathrm{mmHg}$, and SpO2 of 97\%. Significant physical examination findings included nuchal rigidity, swollen lymph nodes in groin area, and vesicular vaginal lesions.

Lab workup that was within normal limits included a complete blood count with differential, complete metabolic panel, lactate, negative urine human chorionic gonadotropin test, and urinalysis. Her serum glucose was $215 \mathrm{mg} / \mathrm{dL}$, which was consistent with her history of poorly controlled type 1 diabetes mellitus. A lumbar puncture was performed, which revealed a cerebral spinal fluid (CSF) glucose of $99 \mathrm{mg} / \mathrm{dL}$ (reference range is $>41 \mathrm{mg} / \mathrm{dL}$ ), protein level of $80 \mathrm{mg} / \mathrm{dL}$ (reference range is $15-45 \mathrm{mg} / \mathrm{dL}$ ), a negative gram 
stain, 4+ white blood cells, and absolute white blood cell count was $8.2 \mathrm{k} / \mathrm{uL}$ without left shift. CSF was sent for culture and nucleic-acid amplification testing (NAAT) analysis for HSV and varicella zoster virus. Blood samples were also sent for bacterial culture and came back negative. A head computed tomography (CT) was unremarkable. The patient's Glasgow Coma Scale score was 15, she clinically appeared to have meningitis, and there was not clinical evidence of encephalitis.

Due to the patient history, clinical presentation, CSF findings, and an immunocompromised state, the patient was admitted to the hospital and initially started on intravenous acyclovir, broad-spectrum antibiotics, and deep vein thrombosis prophylaxis. The patient had reported mild facial swelling from previous treatment with acyclovir; the risks and benefits were weighed and intravenous acyclovir was selected as the best option. The patient's vital signs stabilized within 24 hours of beginning treatment and her headache severity level improved to 1 out of 10 . NAAT analysis of CSF returned positive for HSV-2. The patient steadily improved over her hospital stay, there were no sequelae, and was eventually discharged home after five days with home healthcare follow-up treatment for intravenous acyclovir treatment.

\section{Discussion}

When considering the ED evaluation of central nervous system infections, two of the most concerning differential diagnoses include bacterial meningitis (BM) and HSV-1 encephalitis. BM and HSV-1 may progress rapidly, leading to poor neurologic outcomes [7,9]. While VM is also considered, most cases do not invoke concern for permanent sequelae as the disease course from the causative organisms is generally selflimited [3].

In a patient with poorly controlled diabetes mellitus type 1 , an immunocompromised state promoted the meningeal seeding of her genital HSV-2 infection. Literary sources have identified that untreated HSV-2 meningeal infections may lead to significant morbidity and mortality $[3,4,10]$. The risk of suffering permanent disability from this disease is even greater in immunocompromised patients [10].

Immunocompromised patients are found to have more neurologic sequelae following HSV meningitis than immunocompetent patients [4]. Therefore, it would be prudent for ED physicians to increase their index of suspicion and consider prompt evaluation and therapy for HSV-2 meningitis in any immunocompromised adult with documented HSV-2 infection.

Furthermore, in the outpatient setting, a genital HSV-2 infection is often self-limited in otherwise healthy individuals. Therefore, treatment is often considered elective. Additionally, the role of antivirals to treat meningitis is still unclear [4]. However, this case demonstrates the need to initiate anti-viral treatment for patients who have active HSV-2 genital infections and a low-functioning immune system.

\section{Conclusions}

With population health trends and current evidence, VM may become an increasing concern in years to come. More investigation will need to be done regarding which circumstances lend to early aggressive therapy versus a watch-and-wait approach when it comes to genital HSV-2 outbreaks. Future research will need to elucidate if there are significant differences in risk between first or subsequent outbreak of HSV-2 as well as comorbidities and their time courses that are causing the immunocompromised state. Currently, we advocate for a lower threshold to treat in the outpatient setting and increased index of suspicion in the ED.

\section{Additional Information}

\section{Disclosures}

Human subjects: Consent was obtained or waived by all participants in this study. Conflicts of interest: In compliance with the ICMJE uniform disclosure form, all authors declare the following: Payment/services info: All authors have declared that no financial support was received from any organization for the submitted work. Financial relationships: All authors have declared that they have no financial relationships at present or within the previous three years with any organizations that might have an interest in the submitted work. Other relationships: All authors have declared that there are no other relationships or activities that could appear to have influenced the submitted work.

\section{References}

1. Centers for Disease Control and Prevention (CDC): Outbreaks of aseptic meningitis associated with echoviruses 9 and 30 and preliminary surveillance reports on enterovirus activity--United States, 2003. MMWR Morb Mortal Wkly Rep. 2003, 52:761-764.

2. Cantu RM, Das JM: Viral meningitis. StatPearls [internet]. StatPearls Publishing, Treasure Island, FL; 2020.

3. McGill F, Griffiths MJ, Bonnett LJ, et al.: Incidence, aetiology, and sequelae of viral meningitis in UK adults: a multicentre prospective observational cohort study. Lancet Infect Dis. 2018, 18:992-1003. 10.1016/S14733099(18)30245-7

4. Noska A, Kyrillos R, Hansen G, Hirigoyen D, Williams DN: The role of antiviral therapy in immunocompromised patients with herpes simplex virus meningitis. Clin Infect Dis. 2015, 60:237-242. $10.1093 / \mathrm{cid} / \mathrm{ciu} 772$ 


\section{Cureus}

5. Geerlings SE, Hoepelman AI: Immune dysfunction in patients with diabetes mellitus (DM) . FEMS Immunol Med Microbiol. 1999, 26:259-265. 10.1111/j.1574-695X.1999.tb01397.x

6. Zhou T, Hu Z, Yang S, Sun L, Yu Z, Wang G: Role of adaptive and innate immunity in type 2 diabetes mellitus. J Diabetes Res. 2018, 2018:7457269. 10.1155/2018/7457269

7. Schmidt H, Heimann B, Djukic M, Mazurek C, Fels C, Wallesch CW, Nau R: Neuropsychological sequelae of bacterial and viral meningitis. Brain. 2006, 129:333-345. 10.1093/brain/awh711

8. Landry ML, Greenwold J, Vikram HR: Herpes simplex type-2 meningitis: presentation and lack of standardized therapy. Am J Med. 2009, 122:688-691. 10.1016/j.amjmed.2009.02.017

9. Bradshaw MJ, Venkatesan A: Herpes simplex virus-1 encephalitis in adults: pathophysiology, diagnosis, and management. Neurotherapeutics. 2016, 13:493-508. 10.1007/s13311-016-0433-7

10. Momméja-Marin H, Lafaurie M, Scieux C, Galicier L, Oksenhendler E, Molina JM: Herpes simplex virus type 2 as a cause of severe meningitis in immunocompromised adults. Clin Infect Dis. 2003, 37:1527-1533. $10.1086 / 379520$ 